\title{
- \\ LE RÔLE DES ECTOMYCORHIZES DANS LA NUTRITION AZOTÉE DES ARBRES FORESTIERS
}

\author{
Claude PLASSARD - M. CHALOT - B. BOTTON - F. MARTIN
}

La disponibilité en azote est, avec l'eau, l'un des principaux facteurs limitant la croissance des arbres dans la plupart des écosystèmes forestiers des régions tempérées et boréales. Comme dans tous les écosystèmes, l'existence du cycle de l'azote (figure 1, p. 83) permet le recyclage permanent de cet élément entre des formes organiques produites au cours de la vie des différents organismes de l'écosystème et des formes minérales utilisées par les végétaux. Dans les écosystèmes forestiers, les vitesses de minéralisation de l'azote protéique sont généralement lentes, aboutissant à une accumulation d'azote organique qui peut représenter jusqu'à $90 \%$ de la quantité d'azote total du sol forestier. Mais cet azote organique, séquestré dans la biomasse végétale ou animale, dans la litière ou le sol, est peu accessible aux arbres qui utilisent préférentiellement l'azote inorganique $\left(\mathrm{NH}_{4}^{+}, \mathrm{NO}_{3}^{-}\right)$.

Cependant, dans les écosystèmes non perturbés, les racines des grandes essences sylvicoles des forêts tempérées et boréales (exemple : Pins, Épicéa, Chêne, Hêtre) portent généralement des ectomycorhizes qui peuvent être formées par plusieurs centaines d'espèces de champignons basidiomycètes (exemple: Amanites, Bolets) et ascomycètes (exemple: Truffes). Morphologiquement, on distingue souvent parfaitement une racine courte ectomycorhizée d'une racine courte non mycorhizée par la présence du manteau fongique externe recouvrant la racine mycorhizée (figures 1 et 2, p. 83). Les filaments mycéliens de ce manteau se développent d'une part vers l'intérieur de la racine, en s'insinuant entre les cellules du cortex racinaire et d'autre part vers l'extérieur de la racine pour constituer un réseau extraradiculaire (figure 2, p. 83). Alors que la croissance des hyphes à l'intérieur de la racine est limitée par la présence de l'endoderme, la croissance des filaments externes peut être extrêmement importante (jusqu'à $1000 \mathrm{~m}$ de mycélium/m de racine), augmentant ainsi considérablement le volume de sol prospecté. Si un mycélium qui explore ce volume de sol est capable de mobiliser des éléments minéraux inaccessibles aux racines de la plante-hôte et de les lui fournir, sous leur forme initiale ou après les avoir transformés, à travers les ectomycorhizes, on comprend facilement que l'établissement d'associations symbiotiques mycorhiziennes apparaisse comme une stratégie importante développée par les arbres afin d'assurer leur survie et leur croissance (Harley et Smith, 1983).

Les champignons ectomycorhiziens et les plantes ligneuses avec lesquelles ils s'associent appartiennent à deux groupes végétaux distincts, les thallophytes et les végétaux vasculaires respectivement, et ces végétaux diffèrent fondamentalement entre eux. Par exemple, vis-à-vis du carbone, les 
arbres sont autotrophes alors que les champignons sont hétérotrophes pour cet élément. Dans les associations ectomycorhiziennes, la plante-hôte fournit donc le carbone nécessaire au développement du partenaire fongique. De la même façon que pour le carbone, il est donc envisageable que ces organismes diffèrent dans leurs capacités à utiliser les différentes formes d'azote qui vont se trouver dans un sol. Nous avons vu plus haut qu'il est communément admis que les arbres

\section{Figure 1}

\section{LE CYCLE DE L’AZOTE ET LE RÔLE POTENTIEL DES ECTOMYCORHIZES DANS L'UTILISATION DES DIFFÉRENTES FORMES DE L'AZOTE DU SOL}

Le cycle de l'azote aboutit à la formation d'azote minéral soluble à partir de l'azote protéique contenu dans les débris animaux et végétaux. L'action des ectomycorhizes peut s'effectuer aux différents niveaux indiqués par les flèches en pointillé.

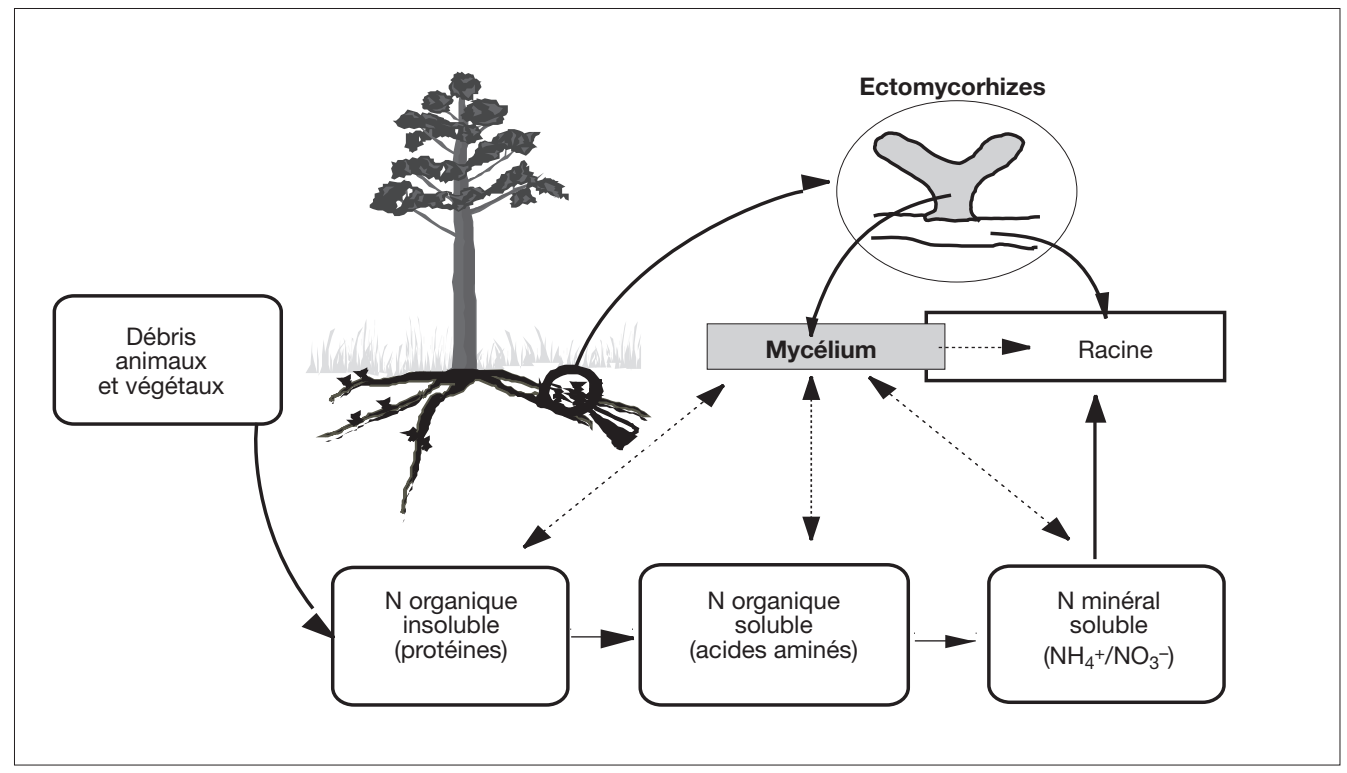

Figure 2 REPRÉSENTATION SCHÉMATIQUE D'UNE COUPE LONGITUDINALE D'UNE RACINE COURTE DE CONIFĖRE NON MYCORHIZÉE (a) ET ECTOMYCORHIZÉE (b)

En absence de mycorhization, la racine courte présente de nombreux poils absorbants qui disparaissent après infection et formation du manteau fongique externe.

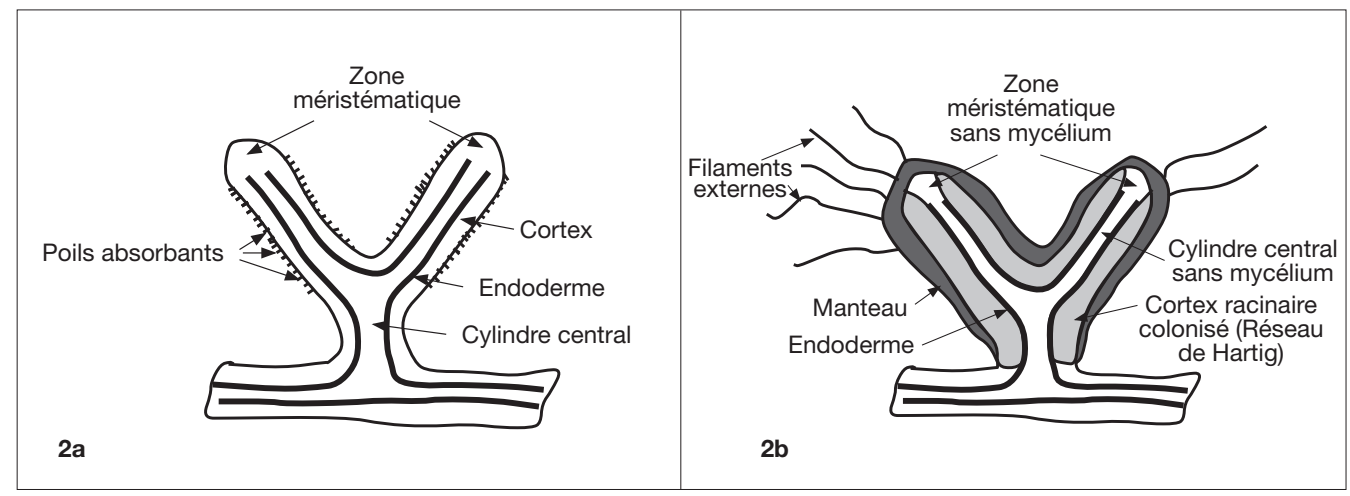


fabriquent leurs protéines (1) principalement à partir de l'azote minéral de la solution du sol. Cependant qu'en est-il des champignons ectomycorhiziens ? Présentent-ils les mêmes caractéristiques ou sont-ils au contraire capables d'utiliser des formes d'azote plus variées, comme par exemple des formes protéiques non accessibles aux végétaux supérieurs? Après avoir mobilisé de l'azote, sont-ils capables de le fournir à la plante-hôte, et si oui sous quelle forme et à quel prix pour la plante ? Et enfin, est-il possible de sélectionner des espèces fongiques efficaces dans l'amélioration de la nutrition azotée des arbres forestiers ? Le but de cet article est de faire le point sur ces questions en s'appuyant sur les résultats obtenus au cours des recherches menées sur les ectomycorhizes durant ces dernières années.

\section{LES MYCORHIZES ET L'AZOTE ORGANIQUE}

L'azote organique peut se trouver principalement sous deux formes: insoluble (les protéines) ou soluble (les petits peptides et les acides aminés ${ }^{(2)}$ ). Les données sur les capacités d'utilisation de ces deux formes d'azote par les champignons ectomycorhiziens et les ectomycorhizes ont largement progressé au cours de ces dernières années et c'est dans cet ordre que nous les évoquerons successivement.

\section{Les protéines}

Dans tout écosystème non perturbé, la première étape de la minéralisation de l'azote est l'hydrolyse des liaisons peptidiques ${ }^{(3)}$ des protéines contenues dans les débris végétaux et animaux sous l'action d'enzymes spécifiques, appelées protéases, pour produire de l'azote organique soluble (figure 1, p. 83). En conditions contrôlées de laboratoire, les arbres non mycorhizés sont généralement incapables de se développer sur des milieux contenant des protéines insolubles comme seule source d'azote, confirmant que leur capacité de production des protéases est très faible. Par contre, la mycorhization des espèces ligneuses permet une croissance de la plante dans ces conditions, indiquant que le symbiote fongique rend l'arbre capable d'utiliser cette source d'azote insoluble (Abuzinadah et Read, 1986). La première hypothèse que I'on peut émettre pour expliquer cette action bénéfique de la symbiose est que le partenaire fongique est capable de produire et d'excréter des protéases dans le milieu, ce qui lui permet de mobiliser l'azote à partir de protéines. La recherche de la capacité de production des protéases a effectivement montré qu'un nombre considérable d'espèces fongiques, dans pratiquement tous les groupes, étaient capables de produire et d'excréter des protéases (Cohen, 1980). De telles enzymes ont été dosées aussi bien chez des champignons éricoïdes comme la Pézize orangée (Hymenoscyphus ericae) (Bajwa et al., 1985) que chez des champignons ectomycorhiziens cultivés en culture pure (Ramstedt et Söderhäll, 1983 ; El-Badaoui et Botton, 1989 ; Zhu et al., 1990).

Après avoir mis en évidence que les champignons ectomycorhiziens étaient capables de produire des protéases extracellulaires, différents travaux ont été menés pour tenter de connaître les conditions de milieu permettant un fonctionnement optimal de ces enzymes. Les résultats obtenus montrent que, chez toutes les espèces fongiques étudiées jusqu'à présent, l'activité protéasique n'est pas réprimée par l'ammonium, que leur $\mathrm{pH}$ optimal de fonctionnement se situe généralement autour de 4,0-4,5 (El-Badaoui et Botton, 1989). Enfin, le facteur le plus important est la présence de protéines exogènes qui est absolument requise pour stimuler les activités protéases excrétées, comme

(1) Protéine : macromolécule constituée d'une suite d'acides aminés reliés entre eux par une liaison peptidique.

(2) Acide aminé : composés élémentaires des protéines ; ils sont caractérisés par un groupe amine (-NH2) et un groupe carboxyle $(-\mathrm{COOH})$.

(3) Liaison peptidique : liaison de type amide substituée entre le groupe carboxyle d'un acide aminé et le groupe amine de l'acide aminé suivant. Cette liaison se fait par élimination d'une molécule d'eau. 
cela a été montré pour Cenococcum geophilum (figure 3, ci-dessous) ou pour Hebeloma crustuliniforme (El-Badaoui et Botton, 1989). Mais la figure 3 montre aussi que toutes les protéines n'ont pas le même effet stimulateur de l'activité puisque la gélatine est un meilleur inducteur que la caséine et l'albumine sérique bovine. Mais cet effet inducteur de la gélatine est encore très largement inférieur à celui d'un groupe de protéines isolées de la litière (figure 4, ci-dessous), ce qui suggère que les champignons ectomycorhiziens sont probablement mieux adaptés à la dégradation des protéines du sol qu'à la dégradation des protéines animales non présentes dans la rhizosphère.

Cependant les résultats de tels travaux, effectués en incubant in vitro les mycelia en présence de protéines purifiées, sont-ils transposables sur le terrain où les protéines de la litière ou du sol ne sont généralement pas sous une forme simple mais plutôt complexées à d'autres composés ? Cette question a été abordée en cultivant, dans des rhizotrons, de jeunes plantules de Pin sylvestre préalablement mycorhizées par le bolet des Pins (Suillus bovinus). Ce dispositif expérimental présente

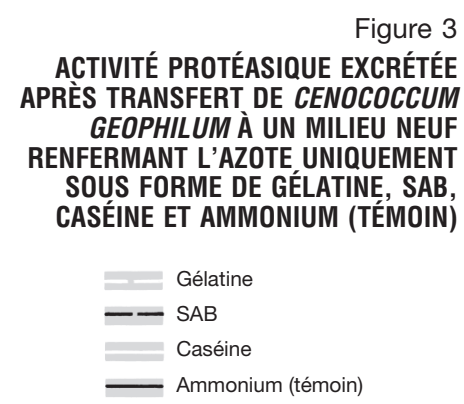

Le transfert des thalles a lieu au temps zéro. Trois grammes de matière fraîche du champignon âgé de 8 jours sont transférés sur $100 \mathrm{ml}$ de milieu de culture renfermant les protéines à la concentration de 0,2\%. Les dosages de l'activité protéasique sont effectués avec la caséine comme substrat.

Figure 4 ACTION COMPARÉE D'UN EXTRAIT DE PROTÉINES DE LA LITIËRE ET DES PROTÉINES COMMERCIALES, GÉLATINE ET SAB, SUR LA PRODUCTION DE PROTÉASES EXOCELLULAIRES CHEZ AMANITA RUBESCENS

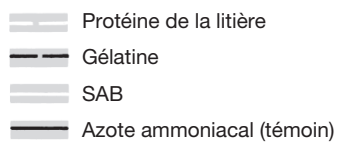

Le milieu de Pachlewski renfermant l'azote ammoniacal est utilisé comme témoin. Les protéines ont été apportées à la concentration de $0,1 \%$. Le dosage des activités protéasiques dans les milieux de culture est effectué par fluorescence avec la FITC-BSA comme substrat.
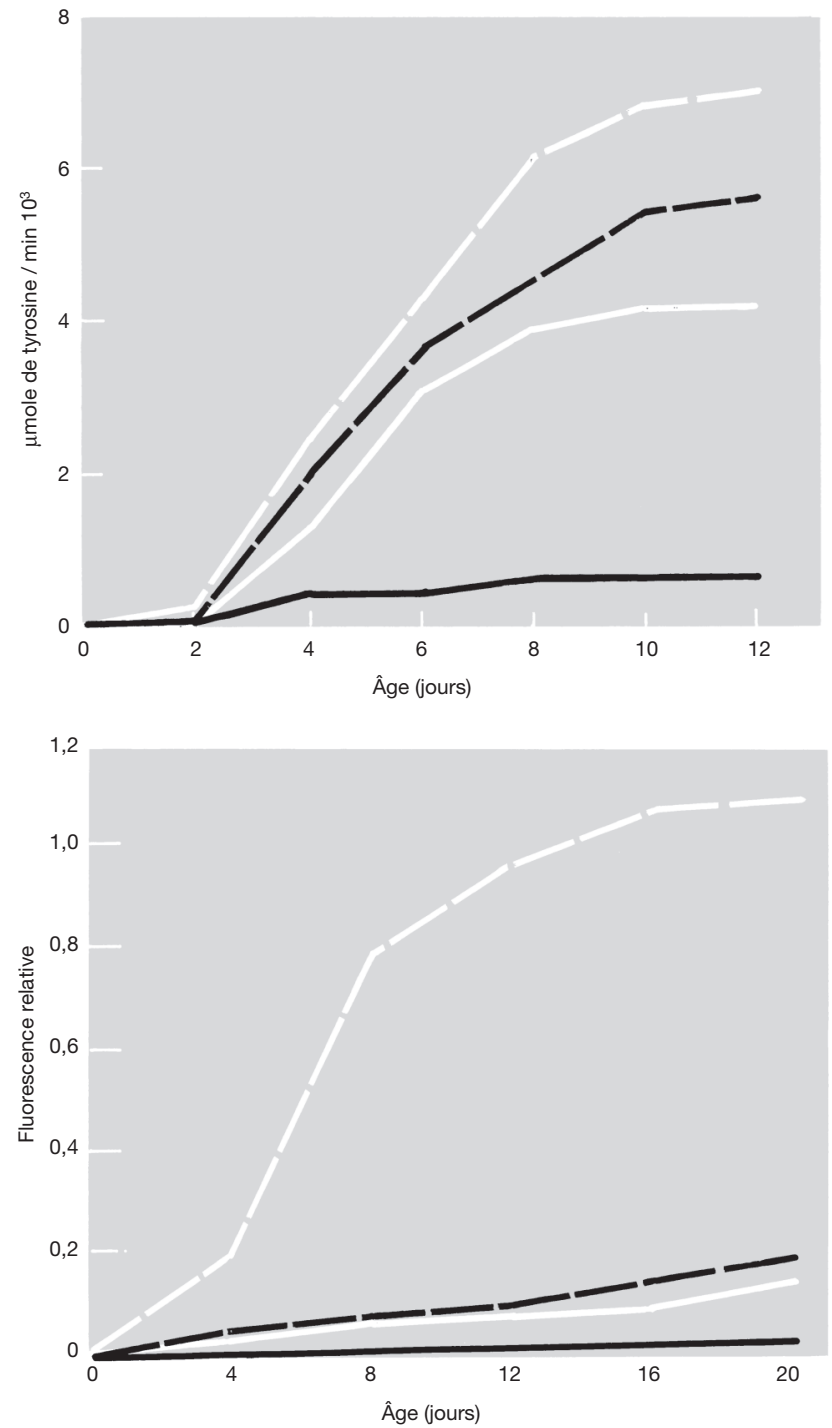
l'avantage de pouvoir suivre le développement du mycélium extraradiculaire associé à la plante-hôte sans perturber le système racinaire, puis d'étudier localement l'effet du développement fongique sur son environnement. Les auteurs de l'étude ont montré que cette espèce fongique est capable de coloniser fortement un substrat provenant d'un horizon de fermentation d'un sol forestier et riche en matière organique déjà transformée. Cette colonisation du substrat s'accompagne d'une exportation des éléments comme $\mathrm{N}, \mathrm{P}$ et $\mathrm{K}$ initialement présents dans la matière organique (Bending et Read, 1995a) et de la production d'activités protéases extracellulaires mesurables dans le substrat (Bending et Read, 1995b). Ces résultats sont donc favorables à l'hypothèse qu'in situ le mycélium d'un champignon ectomycorhizien soit capable d'excréter des protéases lui permettant de mobiliser de l'azote à partir de protéines du sol ou de la litière. Cependant, des travaux récents (Colpaert et al., 1996a,1996b), effectués avec le même type de système expérimental, ont montré que les champignons ectomycorhiziens ne pouvaient pas mobiliser de l'azote directement à partir de feuilles fraîchement tombées sur le sol, contrairement à une espèce saprophyte, le Tricholome nu (Lepista nuda: syn. Tricholoma nudum), qui s'est révélée au contraire très efficace dans la mobilisation de l'azote protéique (Colpaert et al., 1996a, 1996b). L'ensemble de ces résultats suggère donc qu'une étape initiale de décomposition de la matière organique par des champignons saprophytiques est sans doute nécessaire à la libération de l'azote protéique à partir de cette litière fraîche pour que les protéases des champignons ectomycorhiziens puissent agir dans les conditions naturelles.

Néanmoins, la capacité de production des protéases extracellulaires a très probablement une signification écologique car elle reflète la distribution des champignons ectomycorhiziens dans les conditions naturelles. Ainsi, l'Amanite rougissante (Amanita rubescens) et le Lactaire douceâtre (Lactarius subdulcis), normalement présents dans les horizons organiques, ont une plus grande capacité à produire des protéases que Cenococcum geophilum et Hebeloma crustuliniforme qui vivent essentiellement dans les horizons minéraux (tableau I, ci-dessous). De la même façon, les espèces forestières dominantes des régions boréales que sont le Bouleau, l'Épicéa et le Pin, possèdent des ectomycorhizes avec de très fortes activités protéasiques (Read, 1991). Ces essences sont considérées comme très bien adaptées aux sols organiques (Rowe, 1972) car elles peuvent se développer dans cet environnement où les températures basses régnant habituellement entraînent une inhibition des processus de décomposition et de minéralisation, conduisant à une nutrition azotée essentiellement organique. L'association des espèces forestières à des champignons ectomycorhiziens particulièrement efficaces pour utiliser l'azote organique est sans doute indispensable pour conférer "l'adaptation" des essences considérées à ces conditions pédo-climatiques particulières.

Tableau I Croissance et production de protéases par quatre champignons ectomycorhiziens cultivés sur milieux de culture, renfermant comme source d'azote

les protéines extraites de la litière (milieu inducteur) ou de l'ammonium (milieu témoin).

Le dosage des protéases est effectué par fluorométrie avec la FITC-BSA comme substrat (d'après El-Badaoui et Botton, 1989)

\begin{tabular}{|c|c|c|c|}
\hline & & Poids sec (mg) & $\begin{array}{c}\text { Activité protéasique } \\
\text { excrétée par thalle } \\
\text { (fluorescence) }\end{array}$ \\
\hline Cenococcum geophilum & $\begin{array}{l}\text { - induit .... } \\
\text { - témoin .... }\end{array}$ & $\begin{array}{l}20,5 \\
38,9\end{array}$ & $\begin{array}{r}44,0 \\
3,2\end{array}$ \\
\hline Hebeloma crustuliniforme & $\begin{array}{l}\text { - induit ..... } \\
\text { - témoin .... }\end{array}$ & $\begin{array}{l}18,0 \\
34,6\end{array}$ & $\begin{array}{r}30,0 \\
2,9\end{array}$ \\
\hline Amanita rubescens & $\begin{array}{l}\text { - induit ..... } \\
\text { - témoin } \ldots .\end{array}$ & $\begin{array}{l}11,3 \\
18,9\end{array}$ & $\begin{array}{r}198,0 \\
6,9\end{array}$ \\
\hline Lactarius subdulcis & $\begin{array}{l}\text { - induit ..... } \\
\text { - témoin ... }\end{array}$ & $\begin{array}{r}8,6 \\
15,4\end{array}$ & $\begin{array}{r}180,0 \\
5,3\end{array}$ \\
\hline
\end{tabular}




\section{Le fonctionnement des symbioses mycorhiziennes}

\section{Les peptides et les acides aminés}

Une protéolyse active conduit bien évidemment à la production de peptides et d'acides aminés libérés dans la solution du sol. Ce sont ces composés azotés qui vont pouvoir être absorbés on non par les racines ou les micro-organismes du sol, dont les champignons ectomycorhiziens. Quel que soit le composé considéré, il pénètre dans les cellules par des systèmes membranaires spécifiques de type canal ou transporteur (aussi appelé perméase).

Concernant l'absorption des peptides, la majorité des travaux a été effectuée avec des espèces fongiques non mycorhiziennes "modèles" telles que Neurospora crassa et les levures Saccharomyces cerevisiae et Candida albicans (Becker et Naider, 1995). Cependant, I'utilisation de peptides marqués dans le milieu d'incubation du Paxille enroulé (Paxillus involutus) a permis de montrer que leur transport est caractérisé par une phase de latence durant laquelle l'absorption est très inférieure à celle d'un acide aminé. En revanche, après 12 heures d'incubation, l'absorption est égale à celle d'un acide aminé (Chalot, résultats non publiés). La nature des transporteurs mis en jeu ainsi que leur spécificité et le type de peptide transporté restent à élucider.

Concernant l'absorption des acides aminés, l'intervention de systèmes de transport a été démontrée chez les plantes supérieures (Bush, 1993 ; Frommer et al., 1994), les levures et les champignons inférieurs (Horak, 1986 ; Roos, 1989 ; Sophianopoulou et Diallinas, 1995). L'étude approfondie de l'absorption des acides aminés a été menée par Chalot et ses collaborateurs sur le Paxille enroulé (Paxillus involutus) cultivé en culture pure, et ils ont mis en évidence l'existence d'un transporteur général d'acides aminés chez cette espèce fongique (Chalot et al., 1995, 1996). Ce transporteur paraît particulièrement aspécifique car il peut transporter jusqu'à 20 acides aminés différents et présente un fonctionnement optimal situé à des $\mathrm{pH}$ acides voisins de 4,0-4,5, fonctionnement qui n'est pas modifié par la présence d'ammonium ou de nitrate à des concentrations comprises entre 0,5 et $0,05 \mathrm{mM}$ qui peuvent être détectées dans la solution du sol. Ces caractéristiques sont écologiquement importantes car on sait que les $\mathrm{pH}$ des sols forestiers sont très généralement voisins de 4,0-4,5 et que la solution du sol comporte normalement un mélange de composés azotés organiques et inorganiques (Abuarghub et Read, 1988). On peut donc penser qu'un champignon qui possède un tel transporteur d'acides aminés sera capable d'absorber dans des conditions optimales de nombreux acides aminés présents dans la solution du sol. Enfin, les premières données comparatives obtenues par Chalot et ses collaborateurs sur les capacités d'absorption des acides aminés par les racines de Bouleau montrent clairement que les vitesses d'absorption de l'acide glutamique mesurées sur les racines non mycorhizées sont très inférieures à celles mesurées sur le mycélium du Paxille enroulé. Ces propriétés du champignon sont conservées lorsqu'il est associé à la plante-hôte et la vitesse d'absorption mesurée sur les racines mycorhizées, correspondant à la somme des deux composantes racinaire et fongique, est alors 10 fois supérieure à celle mesurée sur les racines non mycorhizées (figure 4, p. 85). En conclusion, et bien que cela reste encore à démontrer in situ, il y a donc tout lieu de penser que les champignons ectomycorhiziens sont effectivement capables de favoriser la croissance de leur plante-hôte en augmentant fortement l'utilisation des formes solubles d'azote organique des sols forestiers.

\section{LES ECTOMYCORHIZES ET L’AZOTE MINÉRAL}

Dans le cycle de l'azote, les acides aminés issus de la protéolyse vont être utilisés par différents micro-organismes du sol pour produire de l'ammonium (ammonification) qui peut être à son tour oxydé par la microflore pour produire le nitrate (nitrification), forme ultime de l'azote minéral. Ces deux sources d'azote minéral vont ensuite être absorbées par les racines, assimilées et incorporées dans des squelettes carbonés produits par la photosynthèse, pour réaliser la synthèse des protéines. Pour bien mettre en évidence et bien comprendre le rôle que peuvent avoir les champignons mycorhiziens et les ectomycorhizes dans l'utilisation de l'azote minéral par les plantes ligneuses, 
nous allons d'abord évoquer les données relatives à l'absorption et à l'assimilation des deux formes de l'azote par les espèces ligneuses et les champignons ectomycorhiziens en culture pure. Puis nous aborderons les données obtenues sur les ectomycorhizes et les plantes mycorhizées, ainsi que les hypothèses permettant d'expliquer le fonctionnement de la symbiose.

\section{Absorption de l'azote minéral}

On a longtemps considéré que les espèces ligneuses étaient bien adaptées à la nutrition ammoniacale car, dans les sols forestiers, l'ion $\mathrm{NH}_{4}{ }^{+}$est souvent la forme d'azote minéral prépondérante et, en absence de fertilisation, le rapport $\mathrm{NH}_{4}{ }^{+} / \mathrm{NO}_{3}{ }^{-}$dans la solution du sol est généralement voisin de 10/1. Du fait de ces faibles concentrations en $\mathrm{NO}_{3}^{-}$, il était communément admis que la production de $\mathrm{NO}_{3}{ }^{-}$par nitrification était inhibée dans la plupart des écosystèmes forestiers (Alexander, 1983). Cependant, des expériences de marquage in situ, effectuées en fournissant du ${ }^{15} \mathrm{~N}$ à des sols de forêts de conifères, ont montré que la nitrification est très active même lorsque le $\mathrm{pH}$ de ces sols est de 3,5 (Stark et Hart, 1997). Ces auteurs ont aussi montré que le nitrate produit par nitrification est aussitôt utilisé et immobilisé par la microflore présente dans ces sols, expliquant les très faibles concentrations mesurées dans la solution du sol. Cependant, les perturbations d'origine anthropologique peuvent changer ces équilibres et les vitesses de minéralisation de l'azote dans les sols forestiers. En particulier, les dépositions continues de nitrate à partir de l'acide nitrique atmosphérique peuvent contribuer à l'enrichissement de la solution du sol en $\mathrm{NO}_{3}{ }^{-}$(Attiwill et Adams, 1993). De fait, les mesures réalisées ces dernières années dans les hêtraies et pessières ont révélé que la concentration en nitrate de la solution du sol était voisine de celle de $\mathrm{NH}_{4}{ }^{+}(100 \mu \mathrm{M})$ ou même 10 fois supérieure (Marschner et al., 1991). D'autre part, toutes les perturbations simples, comme les coupes forestières, modifient transitoirement le cycle de l'azote en augmentant la vitesse de minéralisation et en particulier la nitrification (Attiwill et Adams, 1993). L'idée répandue que le $\mathrm{NO}_{3}{ }^{-}$ ne constitue pas une source d'azote quantitativement importante pour les arbres et les champignons ectomycorhiziens doit donc être considérée comme une simplification. D'ailleurs, en culture pure, de nombreuses espèces de champignons ectomycorhiziens sont capables de croître normalement sur $\mathrm{NO}_{3}{ }^{-}$comme unique source d'azote bien que la majorité des espèces testées préfèrent le $\mathrm{NH}_{4}{ }^{+}$.

Les vitesses d'absorption des deux formes d'azote minéral ont surtout été mesurées chez des conifères, mycorhizés ou non. En examinant les données de la littérature, on peut comprendre pourquoi les espèces ligneuses ont une meilleure croissance sur ammonium que sur nitrate: pour des concentrations équivalentes de chaque source d'azote dans le milieu d'incubation, les racines non mycorhizées des espèces étudiées absorbent l'ion $\mathrm{NH}_{4}{ }^{+}$jusqu'à 20 fois plus vite que le $\mathrm{NO}_{3}{ }^{-}$ (Plassard et al., 1991; Kronzucker et al., 1997). Cependant, même si les champignons cultivés sur milieu synthéthique absorbent aussi plus vite $\mathrm{NH}_{4}{ }^{+}$que $\mathrm{NO}_{3}{ }^{-}$, les vitesses mesurées sont du même ordre de grandeur que celles données chez les végétaux herbacés et 10 à 20 fois plus élevées que celles mesurées chez les arbres-hôtes (Plassard et al., 1991). Compte tenu des propriétés des espèces fongiques, on peut donc s'attendre à ce que la présence d'un partenaire fongique stimule l'absorption des deux formes d'azote minéral par le système racinaire. Cet effet stimulateur a été effectivement observé pour l'absorption de $\mathrm{NH}_{4}{ }^{+}$(France et Reid, 1983 ; Rygiewicz et al., 1984a) ou de $\mathrm{NO}_{3}^{-}$(France et Reid, 1983 ; Plassard et al., 1994). Cependant, une étude détaillée de l'absorption de $\mathrm{NO}_{3}{ }^{-}$effectuée à l'aide de l'isotope ${ }^{15} \mathrm{~N}$ sur des conifères de la côte Pacifique américaine (Douglas, Épicéa de Sitka, Pruche de l'Ouest), associés ou non à l'Hébélome échaudé (Hebeloma crustuliniforme), a aussi démontré que la stimulation de l'absorption de l'azote inorganique dépend de la plante-hôte considérée. La stimulation de l'absorption de $\mathrm{NO}_{3}{ }^{-}$ne s'observe que chez le Sapin de Douglas (Rygiewicz et al., 1984b) révélant de profondes différences dans le comportement des espèces. Pour une même plante-hôte, l'amélioration de l'absorption de $\mathrm{NO}_{3}{ }^{-}$(figures 5 et $6 \mathrm{~A}, \mathrm{p} .89$ ) ou de $\mathrm{NH}_{4}{ }^{+}$(figure $6 \mathrm{~B}$, p. 89) dépend aussi de l'espèce de champignon associé. L'ensemble de ces données suggère donc que les interactions plante/champignon sont complexes dès la première étape de l'utilisation de l'azote minéral. 


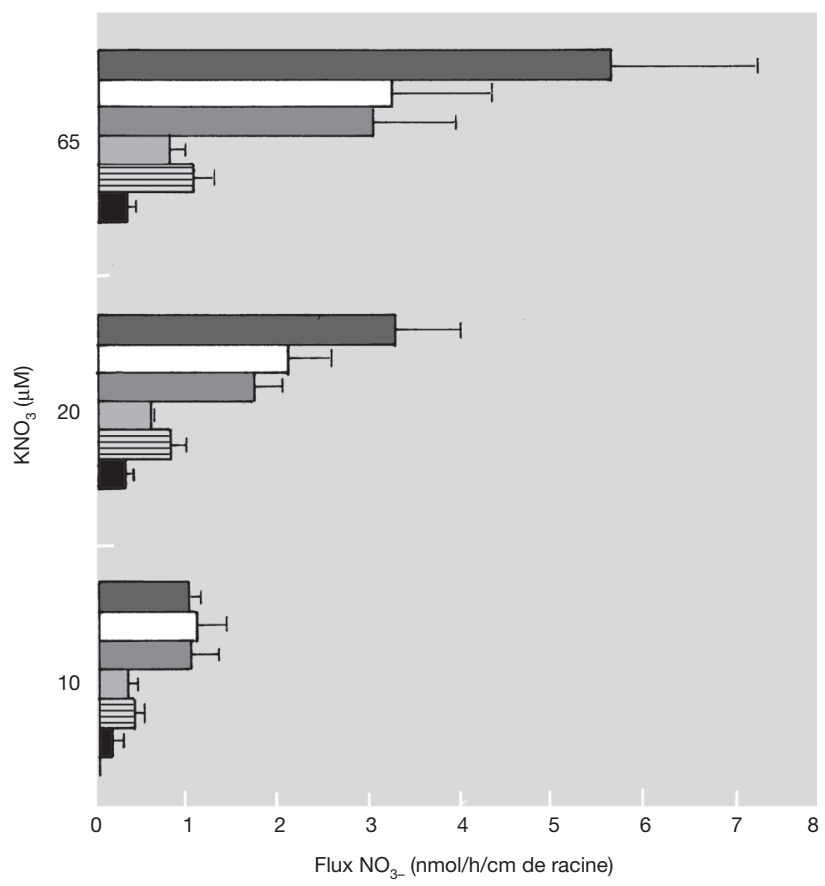

Figure 5

FLUX DE $\mathrm{NO}_{3}{ }^{-}$,

mesurés à l'aide de micro-électrodes spécifiques, à la surface de différents types de racines du Pin maritime non mycorhizé (apex racine longue, racines courtes) ou mycorhizé (racines courtes mycorhizées par Hebeloma cylindrosporum, Suillus collinitus, Rhizopogon rubescens ou Rhizopogon roseolus) en fonction de la concentration en $\mathrm{KNO}_{3}$ dans la solution (Plassard, données non publiées)

Rhizopogon roseolus

Rhizopogon rubescens

Suillus collinitus

Hebeloma cylindrosporum

Racines courtes

Apex racine longue

Figure 6

LA PRÉSENCE D'UN CHAMPIGNON MYCORHIZIEN STIMULE L'ABSORPTION DE L'ION AMMONIUM ET DU NITRATE PAR EUCALYPTUS GLOBULUS BICOSTATA

De jeunes plantules d'Eucalyptus non mycorhizées ou mycorhizées par le Pisolithe, le Scléroderme, l'Hydnangium, ont été alimentées pendant 1 semaine par une solution nutritive enrichie en ${ }^{15} \mathrm{NH}_{4}^{+}$ou ${ }^{15} \mathrm{NO}_{3}^{-}$. L'azote 15 incorporé a ensuite été quantifié dans les plantules par spectrométrie de masse

(Martin, Dell et al., non publié)
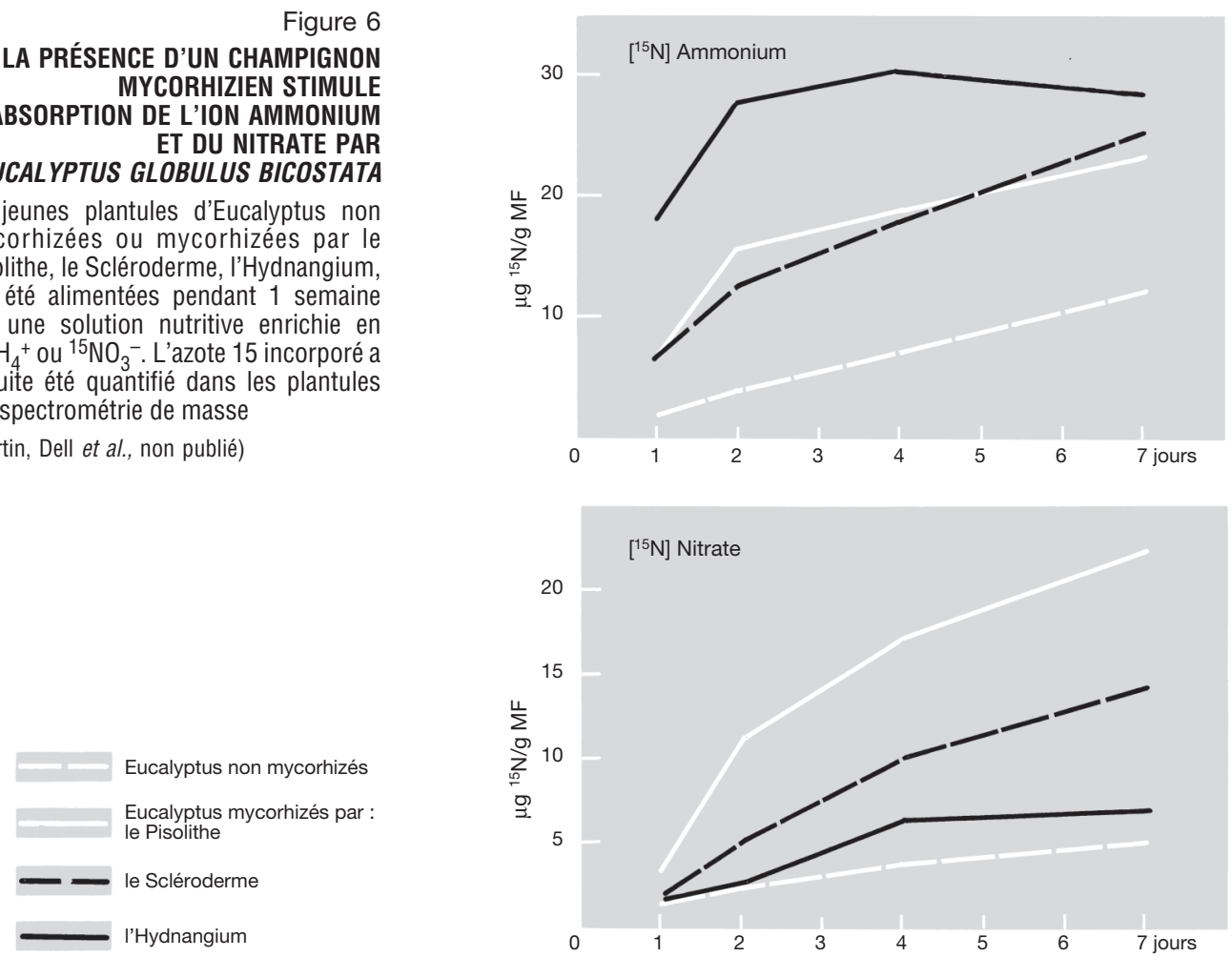


\section{ASSIMILATION DE L’AZOTE MINÉRAL}

Après absorption par les cellules fongiques et/ou racinaires, les deux formes d'azote minéral vont être assimilées par différents systèmes enzymatiques. Le nitrate va être réduit en ammonium et l'ammonium provenant de la réduction du nitrate ou du milieu extérieur va être incorporé à des squelettes carbonés pour produire les acides aminés nécessaires à la synthèse protéique (figure 7 , ci-dessous). Dans les paragraphes qui vont suivre, nous allons aborder les connaissances relatives aux processus d'assimilation des deux formes d'azote minéral (voies enzymatiques mises en jeu, localisation dans la plante) qui ont été déterminées chez les deux partenaires de la symbiose cultivés séparément avant d'évoquer ce que l'on connaît actuellement sur le fonctionnement enzymatique des ectomycorhizes.

Figure 7

\section{SCHÉMA DES VOIES D'ASSIMILATION DE L'AZOTE NITRIQUE ET AMMONIACAL}

NR : nitrate réductase ; NiR : nitrite réductase ; GDH : glutamate déshydrogénase ;

GS : glutamine synthétase ; GOGAT : glutamate synthase.

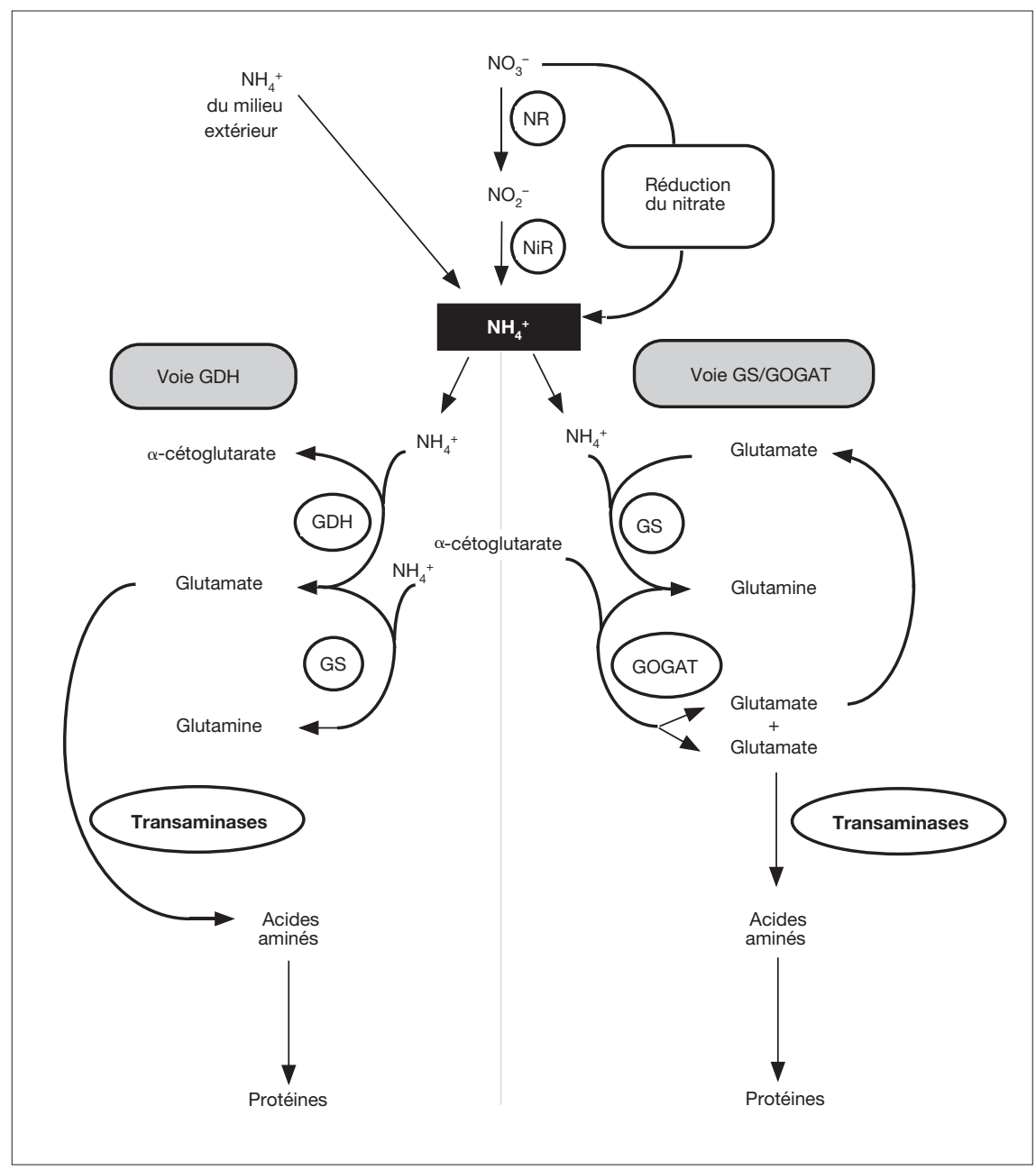




\section{Le fonctionnement des symbioses mycorhiziennes}

\section{La réduction du nitrate}

L'assimilation du $\mathrm{NO}_{3}{ }^{-}$débute par l'activité séquentielle de la nitrate réductase (NR) et de la nitrite réductase (NiR) (figure 7, p. 90). Chez les végétaux supérieurs, on considère que l'étape limitante de la réduction du nitrate est la nitrate réductase et on mesure généralement son activité pour connaître la capacité d'un tissu à assimiler cette source d'azote. À cet effet, deux méthodes sont principalement utilisées pour évaluer l'activité de la NR : la méthode in vitro, où les tissus sont broyés dans un tampon afin d'obtenir un extrait cellulaire contenant l'enzyme. Cet extrait est ensuite incubé avec tous les substrats permettant une activité enzymatique maximale. Dans ces conditions, l'activité mesurée est proportionnelle à la quantité d'enzyme présente dans l'extrait. Au contraire, dans la méthode in vivo, les tissus ne sont pas broyés mais simplement fractionnés et incubés sous vide dans un tampon contenant le substrat principal de l'enzyme, le nitrate. Cette méthode est moins exacte que la méthode in vitro car l'activité mesurée peut dépendre en grande partie de la pénétration du substrat jusqu'au site de l'enzyme. Cependant, chez les arbres, c'est cette deuxième méthode qui est généralement utilisée pour mesurer l'activité NR, car la présence d'inhibiteurs libérés au cours du broyage conduit à la sous-estimation de cette activité enzymatique. Chez les conifères, on trouve généralement que l'activité NR mesurée dans les racines est beaucoup plus importante que dans les parties aériennes (Plassard et al., 1991), suggérant que la majeure partie de la réduction du nitrate a lieu dans les racines. Cependant, d'après Andrews (1986), les espèces pérennes des régions tempérées assimilent le $\mathrm{NO}_{3}{ }^{-}$dans leurs racines quand la concentration en $\mathrm{NO}_{3}{ }^{-}$du sol est faible $\left(<1 \mathrm{~mol} / \mathrm{m}^{3}\right)$. Quand cette concentration augmente, la réduction du $\mathrm{NO}_{3}{ }^{-}$dans les parties aériennes s'accroît. Cependant, l'étude de la distribution de l'activité NR entre racines et feuilles d'arbres tropicaux et subtropicaux indique qu'environ $30 \%$ de ces espèces présentent un rapport NR foliaire / NR racinaire inférieur à un, $40 \%$ un rapport compris entre un et cinq et enfin les $30 \%$ restants un rapport supérieur à 5 (Stewart et al., 1989 ; Gojon et al., 1994). De plus, la plupart des espèces examinées présente des changements marqués dans cette distribution de l'activité $\mathrm{NR}$ lorsque la disponibilité en $\mathrm{NO}_{3}{ }^{-}$augmente. Les espèces qui possèdent une activité NR foliaire très élevée sont des arbres de bordures, de clairières ou se développant au cours des stades initiaux de reforestation et, de ce fait, exposés à de fortes intensités lumineuses.

Chez les champignons ectomycorhiziens, des activités NR ont été mesurées in vitro chez plusieurs espèces, ce qui est en accord avec le fait que ces espèces sont capables de se développer en présence exclusive de nitrate dans leur milieu de culture. Cette activité est très facilement mesurable car elle est très stable. D'importantes variations quantitatives de l'activité NR peuvent exister, d'une part à l'intérieur d'une même espèce fongique, comme l'Hébélome (Hebeloma cylindrosporum) (Wagner et al., 1989) et d'autre part entre différentes espèces fongiques (Plassard et al., 1986), suggérant que tous les isolats d'une même espèce ou d'espèces différentes peuvent présenter des aptitudes variables à assimiler le nitrate. L'activité NiR a été mesurée uniquement chez l'Hébélome, in vitro et in vivo. Contrairement à ce qui est observé pour la NR, l'activité NiR mesurée in vitro est très instable malgré les nombreux composés protecteurs ajoutés au milieu d'extraction (Plassard et al., 1984) alors que, mesurée in vivo, elle est extrêmement stable. La vitesse de réduction du $\mathrm{NO}_{2}^{-}$ peut être deux à trois fois supérieure à la vitesse de réduction du $\mathrm{NO}_{3}{ }^{-}$mesurée dans les mêmes thalles, suggérant qu'in situ, l'activité NiR n'est pas limitante.

\section{L'assimilation de l'ammonium}

La principale caractéristique de l'ion $\mathrm{NH}_{4}{ }^{+}$est qu'il ne peut s'accumuler à l'état libre dans les cellules végétales et doit donc être immédiatement incorporé dans des squelettes carbonés pour produire des acides aminés. On a longtemps considéré que la formation réversible de glutamate ${ }^{(4)}$ à partir de l'ion $\mathrm{NH}_{4}{ }^{+}$et de l' $\alpha$-cétoglutarate (5) (figure 7, p. 90), catalysée par la glutamate déshydrogénase (GDH),

(4) Glutamate : acide aminé ayant deux groupes carboxyle.

(5) $\alpha$-cétoglutarate : acide organique du cycle de Krebs. 
était la voie principale d'incorporation de l'ammonium dans les molécules organiques (Sims et Folkes, 1964). Cependant, une étude cinétique de l'apparition des produits marqués au ${ }^{15} \mathrm{~N}$ après fourniture de ${ }^{15} \mathrm{NH}_{4}{ }^{+}$à des cellules végétales a montré que la glutamine ${ }^{(6)}$, et non le glutamate, était le premier composé marqué. Une autre voie a donc été proposée à partir des années 1970, faisant intervenir la glutamine synthétase ou GS qui catalyse la formation de glutamine à partir de l'ammonium et du glutamate ; la glutamine est ensuite transformée en glutamate par la glutamate synthase ou GOGAT (figure 7, p. 90). D'autre part, il faut noter que la GDH est peu affine pour son substrat car de fortes concentrations en $\mathrm{NH}_{4}{ }^{+}(2$ à $50 \mathrm{mM})$ sont nécessaires pour que l'enzyme fonctionne à la moitié de sa vitesse maximale alors que, pour la GS, des concentrations en $\mathrm{NH}_{4}{ }^{+}$mille fois inférieures $(10$ à $50 \mu \mathrm{M})$ sont suffisantes pour atteindre la moitié de la vitesse maximale. Ces données enzymologiques sont donc aussi en accord avec une assimilation primaire de l'ammonium par la GS et non pas par la GDH.

Chez les plantes supérieures, il est généralement admis que l'assimilation de l'ammonium suit préférentiellement la voie GS/GOGAT (Miflin et Lea, 1980 ; Wallsgrove, 1987). II en est de même chez les végétaux ligneux car l'activité GS a été détectée dans les parties foliaires et racinaires du Pin (Vézina et Margolis, 1990) et dans les racines de Douglas (Bedell et al., 1995), matériels à partir desquels l'enzyme a été purifiée. Toutefois, les racines des espèces ligneuses, comme celles des végétaux supérieurs, révèlent fréquemment des activités GDH à NAD ${ }^{(7)}$ élevées, ce qui pose le problème du rôle de cette enzyme dans ces tissus. L'hypothèse la plus souvent émise est que la GDH à NAD aurait essentiellement une fonction de désamination du glutamate et jouerait un rôle en approvisionnant le cycle de Krebs en $\alpha$-cétoglutarate lorsque la carence carbonée se fait sentir (Oaks et Hirel, 1985 ; Robinson et al., 1991). Cependant, il n'est pas exclu que la GDH à NAD puisse également jouer un rôle de détoxication de la cellule lorsque la teneur en ammonium est élevée.

Chez les champignons ectomycorhiziens en culture pure, une activité glutamate déshydrogénase différant de celle des végétaux supérieurs par le cofacteur utilisé (NAD chez les végétaux supérieurs et NADP (8) chez les champignons mycorhiziens) a été mesurée in vitro chez plusieurs espèces fongiques. Cependant, les études utilisant l'isotope ${ }^{15} \mathrm{~N}$, les dosages enzymatiques et les inhibiteurs enzymatiques indiquent que les deux voies d'assimilation de l'ammonium (GDH à NADP, GSGOGAT) peuvent être impliquées dans l'assimilation de l'ammonium par les cellules fongiques, ceci en fonction des espèces (Martin et Botton, 1993 ; Botton et Chalot, 1995). En outre, pour une même espèce fongique, le fonctionnement de l'une ou l'autre voie peut dépendre des conditions de milieu (en particulier de la concentration externe en $\mathrm{NH}_{4}{ }^{+}$) ou de la phase de croissance mycélienne (Genetet et al., 1984). Ces données indiquent donc que les champignons ectomycorhiziens possèdent une certaine plasticité dans l'assimilation de l'ammonium, ce qui pourrait leur permettre de s'adapter à une grande variété de conditions écologiques.

\section{Assimilation de l'azote par les ectomycorhizes : données enzymologiques}

À l'heure actuelle, on ne dispose pas de données sur le rôle des enzymes fongiques dans l'assimilation du nitrate par les ectomycorhizes. Contrairement au nitrate, l'assimilation de l'ammonium a été plus étudiée. Elle est donc la résultante des transformations opérées par la plante et le champignon mais l'analyse de l'expression de quelques enzymes indique que le tissu symbiotique n'est pas simplement la juxtaposition des deux métabolismes. Actuellement, trois modèles de fonctionnement des ectomycorhizes ont été proposés pour rendre compte des différents équipements enzymatiques des symbiotes (figure 8, p. 94).

(6) Glutamine : acide aminé ayant un groupe amine et un groupe amide $\left(0=\mathrm{C}-\mathrm{NH}_{2}\right)$.

(7) NAD : coenzyme ou composé jouant le rôle de métabolite de transfert (Nicotinamide-Adénine-Dinucléotide).

(8) NADP : autre coenzyme jouant le rôle de métabolite de transfert (Nicotinamide-Adénine-Dinucléotide-Phosphate). 
Figure 8

\section{DIFFÉRENTS SCHÉMAS DE COMPARTIMENTATION DES ENZYMES DE L'ASSIMILATION \\ DE L'AZOTE ENTRE LA RACINE ET LE CHAMPIGNON ECTOMYCORHIZIEN ASSOCIÉ}

(d'après Botton et al., 1994)

\section{A - Ectomycorhizes de Hêtre}

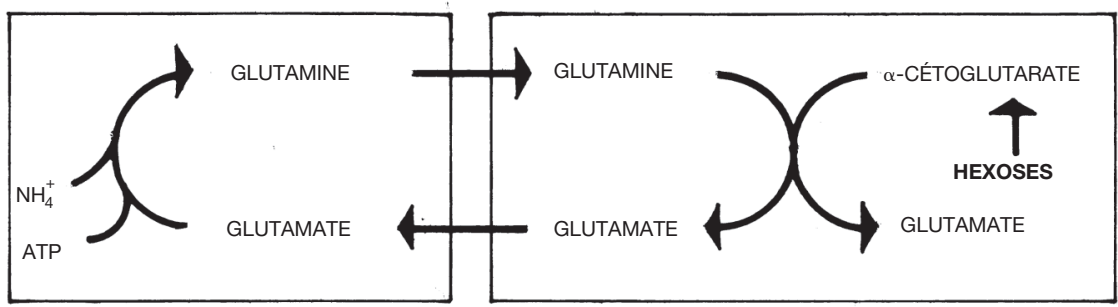

B - Ectomycorhizes d'Épicéa

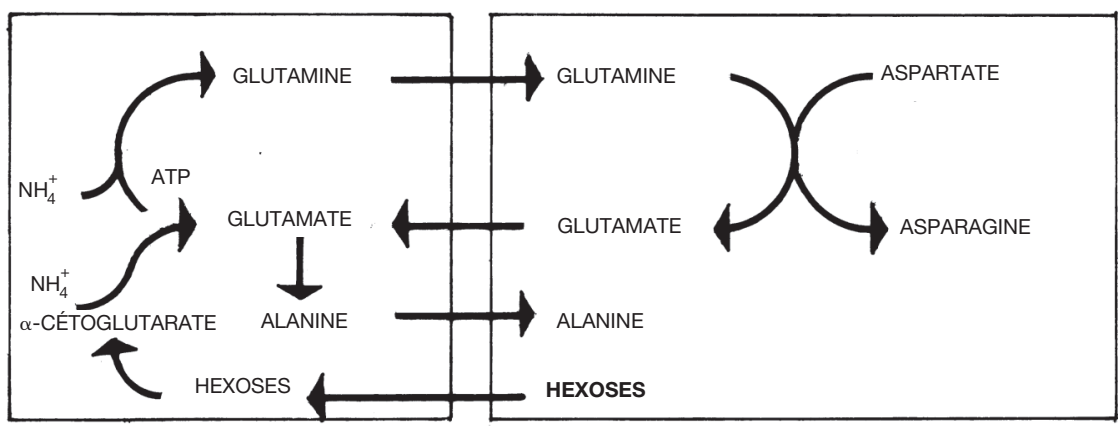

C - Racines mycorhizées par le Pisolithe ou le Paxille enroulé

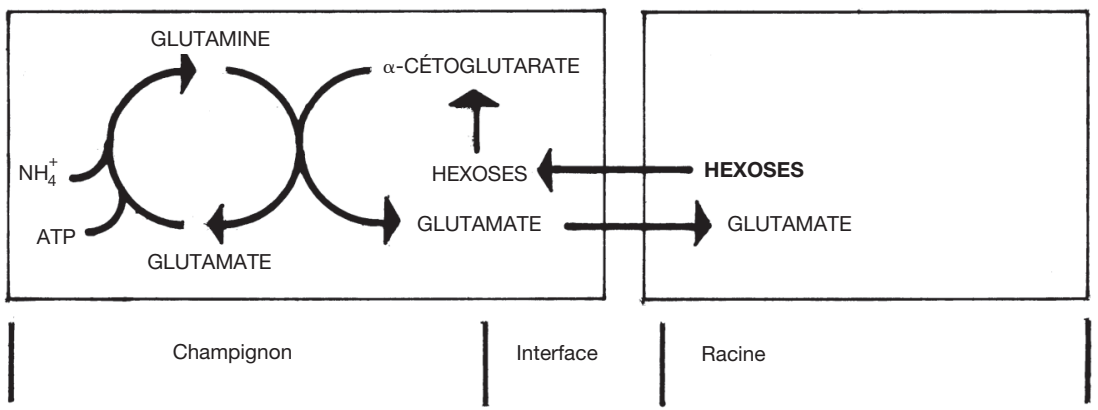

Dans le premier modèle, représenté jusqu'à présent par les ectomycorhizes de Hêtre et l'association entre l'Eucalyptus et le Laccaire laqué (Laccaria laccata), l'absence de GDH à NADP dans le compartiment fongique apparente leur fonctionnement à celui d'une plante (figure 8A, ci-dessus). Le marquage rapide avec l'isotope ${ }^{15} \mathrm{~N}$ indique que la GS est pleinement fonctionnelle (Martin et al., 1986). Avec la GS dans les cellules fongiques et un cycle GS/GOGAT dans les cellules de la plante, une navette glutamine-glutamate rendrait compte d'une accumulation de glutamate et de ses dérivés, alanine ${ }^{(9)}$ et aspartate dans la racine. L'accumulation de glutamine dans le manteau fongique

$\overline{\text { (9) Alanine : acide }}$ aminé à trois atomes de carbone. 
est bien étayée par les résultats expérimentaux (Harley, 1978 ; Martin et al., 1986) et les cinétiques d'accumulation et de marquage des acides aminés sont en faveur d'un transport de glutamine en direction de la plante (France et Reid, 1983 ; Martin et al., 1987 ; Finlay et al., 1988).

Dans le deuxième modèle, représenté par les ectomycorhizes d'Épicéa et de Douglas et par l'association Eucalyptus/Hébélome (Hebeloma westraliense), la présence d'une GDH à NADP opérationnelle dans le champignon rend le métabolisme assimilable à celui rencontré chez la majorité des champignons supérieurs (figure 8B, p. 93) et implique un approvisionnement en squelettes carbonés provenant de la plante.

Dans le troisième modèle, la mise en évidence récente d'un cycle GS/GOGAT chez le Pisolithe (Pisolithus tinctorius), l'Amanite (Amanita), Elaphomyces et Gautieria et existant vraisemblablement chez d'autres champignons tels que le Paxille enroulé (Paxillus involutus) et Cenococcum geophilum, donne à penser que la glutamine et le glutamate sont tous deux synthétisés dans le compartiment fongique. Ces deux acides aminés, avec l'alanine, pourraient être transférés à la plante en échange des squelettes carbonés (figure 8C, p. 93).

\section{LES TRANSFERTS D'AZOTE ENTRE LES PARTENAIRES}

D'après les paragraphes précédents, il est clair que le partenaire fongique est capable de mobiliser de l'azote à partir de sources azotées organiques (protéines, peptides, acides aminés) ou minérales (nitrate, ammonium) et qu'il possède généralement tout l'équipement enzymatique nécessaire pour absorber et assimiler l'azote provenant de ces différentes sources qui vont être disponibles soit au niveau du mycélium extraradiculaire, soit au niveau des ectomycorhizes (figure 8, p. 93). Et finalement, l'efficacité d'un partenaire fongique dépendra en grande partie de sa capacité à transférer à sa plante-hôte l'azote qu'il aura préalablement mobilisé, prélevé et/ou assimilé. Cette capacité de transfert est sans aucun doute un des éléments "clef" de la compréhension du fonctionnement symbiotique et c'est pourquoi nous allons évoquer les données expérimentales disponibles à ce sujet.

\section{Mise en évidence des transferts d'azote entre partenaires de la symbiose}

L'utilisation d'un dispositif expérimental avec deux compartiments distincts, un compartiment racinaire (contenant les racines ectomycorhizées) et un compartiment fongique excluant les racines (Finlay et al., 1989), a permis d'étudier l'effet du partenaire fongique sur l'utilisation de l'azote minéral par des plantes intactes. L'espèce fongique majoritairement utilisée dans ces études est le Paxille enroulé associé à différentes espèces de plantes-hôtes comme le Pin sylvestre (Pinus sylvestris), le Hêtre (Fagus sylvatica) et le Bouleau (Betula pendula). Dans ce dispositif, différentes sources d'azote minéral, marqué au ${ }^{15} \mathrm{~N}$, sont fournies spécifiquement au mycélium mycorhizogène afin de suivre la translocation de l'azote vers les différentes parties des plantes connectées à ce mycélium par leurs ectomycorhizes. Dans tous les cas, la capacité du mycélium à absorber, à assimiler et à transférer de l'azote provenant du ${ }^{15} \mathrm{NH}_{4}{ }^{+}$jusqu'à la plante-hôte a été démontrée (Finlay et al., 1988, 1989 ; Ek, 1997). II en est de même pour l'azote provenant du ${ }^{15} \mathrm{NO}_{3}{ }^{-}$bien que, pour des concentrations en azote minéral identiques (de l'ordre de $15 \mathrm{mM}$ ), les quantités totales d'N- $\mathrm{NO}_{3}$ mesurées dans la plante et le mycélium ne représentent que $62 \%$ des quantités provenant du ${ }^{15} \mathrm{~N}-\mathrm{NH} 4+$ (Finlay et al., 1989), ce qui est en accord avec les données obtenues sur les espèces fongiques en culture pure. Par contre, si les deux sources d'azote minéral sont fournies simultanément au mycélium, l'ammonium est toujours absorbé et assimilé dans le mycélium alors que le nitrate absorbé par le mycélium est transféré à la plante-hôte sous forme de nitrate (Ek et al., 1994). Dans ces conditions expérimentales bien précises, les enrichissements en ${ }^{15} \mathrm{~N}$ des acides aminés mesurés dans le mycélium indiquent que le nitrate a été réduit dans la plante-hôte (probablement dans ses racines) et retransféré dans le mycélium (Ek et al., 1994). Cependant, dans ce dernier cas de figure, le bilan net de transfert de composés azotés reste en faveur de la plante-hôte. 
Les interactions carbone-azote : facteurs de régulation?

Toutes les données précédentes indiquent que le mycélium est généralement nettement plus efficace pour prélever l'azote, minéral en particulier, que les racines non mycorhizées de sa plante-hôte. Pour une espèce fongique donnée, il va donc s'établir un équilibre entre la croissance mycélienne qui va dépendre à la fois des ressources en azote du milieu et des composés carbonés fournis par la plante-hôte, ces deux facteurs pouvant aussi avoir des interactions entre eux. En particulier, il semble que l'ampleur du développement mycélien à l'extérieur de la racine pour coloniser le milieu soit un facteur très important de l'effet du partenaire fongique sur la croissance de la plante-hôte. Colpaert et ses collaborateurs (1992) ont en effet montré qu'il existait une corrélation négative entre la croissance du Pin sylvestre et la biomasse totale mycélienne produite par différentes espèces fongiques inoculées à la plante. D'autre part, les teneurs en azote mesurées dans les plantes ectomycorhizées étaient significativement plus faibles que celles des plants témoins, suggérant que le mycélium avait utilisé l'azote du milieu pour sa propre croissance, elle-même favorisée par les conditions expérimentales utilisées. Ces conditions expérimentales étaient caractérisées par une forte intensité lumineuse et une faible disponibilité en azote minéral. L'intensité lumineuse a probablement favorisé la production de carbone photosynthétique qui a pu être utilisé par le mycélium pour assimiler très efficacement l'azote du milieu aux dépens de la plante-hôte avec laquelle il se trouve alors en compétition. L'importance de ces interactions a aussi été démontrée dans le cas du Pin maritime cultivé en conditions non limitantes en azote minéral $(5 \mathrm{mM})$ et associé à quatre espèces fongiques (Conjeaud, 1996). Après 6 mois de culture, les effets de l'inoculation variaient considérablement avec l'espèce fongique : ainsi l'Hébélome ( $H$. cylindrosporum) avait significativement diminué la croissance de la plante-hôte de $30 \%$ alors que Rhizopogon (R. rubescens) l'avait augmentée de $50 \%$. Ces variations d'accroissement en matière sèche, calculées par rapport aux plants témoins, étaient très fortement corrélées positivement avec l'accroissement en azote total des plantes et négativement avec les pertes respiratoires en carbone des racines (Conjeaud, 1996). D'autre part, le mycélium extraradiculaire de l'Hébélome était très important, sans cordons, alors que celui de Rhizopogon était faible et avec de nombreux cordons. Dans le cas du Pin maritime, deux comportements fongiques tout à fait différents ont donc été observés: un comportement négatif (Hébélome), résultant sans doute d'une croissance et d'une immobilisation de l'azote dans le mycélium avec une utilisation très importante des ressources carbonées de la plante via une biomasse fongique et une respiration très importantes; un comportement positif (Rhizopogon), qui peut résulter d'une faible immobilisation d'énergie et d'azote dans les filaments mycéliens combinée à une utilisation accrue de l'azote du milieu par la plante-hôte. L'ensemble de ces résultats illustre donc l'importance des relations carbone-azote qui vont s'établir entre les partenaires d'une association ectomycorhizienne car leur intensité risque finalement de déterminer l'efficacité de la symbiose.

\section{CONCLUSIONS ET PERSPECTIVES}

Les données acquises au cours de ces dernières années démontrent clairement que les champignons ectomycorhiziens ont des équipements enzymatiques souvent différents de ceux des planteshôtes avec lesquelles ils s'associent, leur permettant d'avoir une meilleure adaptation à des conditions écologiques très variées. Dans ce cadre, l'utilisation des potentialités des milliers d'espèces fongiques disponibles pour améliorer la croissance de la plante-hôte à travers la mycorhization contrôlée est une idée séduisante. Cependant, elle signifie qu'il faut pouvoir disposer d'espèces fongiques efficaces et compétitives. Or, toutes les données expérimentales que nous avons évoquées dans ce chapitre montrent bien que le fonctionnement de la plante mycorhizée ne va pas correspondre simplement à l'addition des propriétés des deux partenaires mis en présence mais le plus souvent à un nouveau fonctionnement résultant du dialogue instauré entre les deux partenaires. Et, pour l'instant, nous manquons encore de critères physiologiques simples, qui nous permettent de prévoir le comportement du partenaire fongique en association à partir des propriétés mises en 


\section{Claude PLASSARD - M. CHALOT - B. BOTTON - F. MARTIN}

évidence par une culture fongique pure et des mesures in vitro. II est cependant probable que l'étude fine, tant au niveau cellulaire que moléculaire, des mécanismes qui vont réguler les échanges de composés azotés et carbonés entre les cellules fongiques et racinaires apportera d'importants éléments de réponse qui devraient permettre de sélectionner rapidement des souches fongiques efficaces. Cependant, à l'heure actuelle, rien ne remplace encore l'étude du comportement de la plante mycorhizée en conditions contrôlées ou sur le terrain, pour pouvoir juger de l'efficacité de l'inoculation ectomycorhizienne.
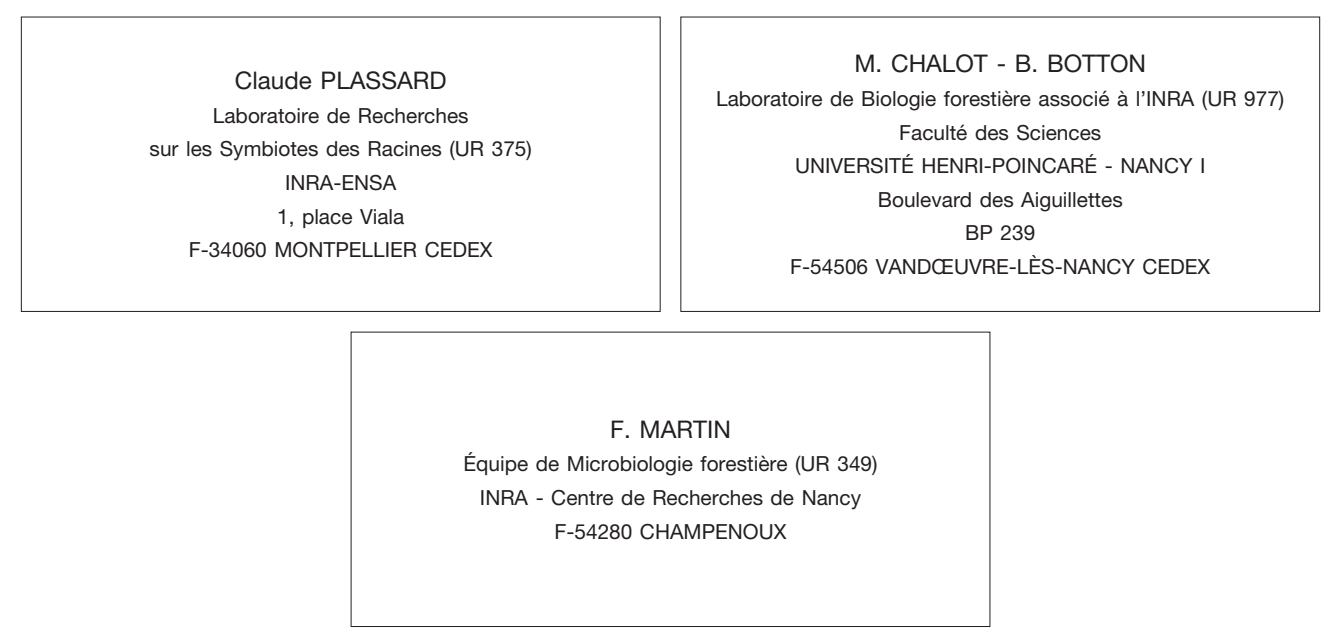

\section{BIBLIOGRAPHIE}

ABUARGHUB (S.M.), READ (D.J.). - The biology of mycorrhiza in the Ericaceae. XII. Quantitative analysis of individual free amino acids in relation to time and depth in the soil profile. - New Phytol., vol. 108, 1988, pp. 433-441.

ABUZINADAH (R.A.), READ (D.J.). - The role of proteins in the nitrogen nutrition of ectomycorrhizal plants. III. Protein utilization by Betula, Picea and Pinus in mycorrhizal association with Hebeloma crustuliniforme. - New Phytol., vol. 103, 1986, pp. 507-514.

ALEXANDER (I.J.). - Ectomycorrhizas in the nitrogen cycle. In : Nitrogen as an ecological factor/ J.A. Lee, S. Mc Neill, I.H. Morison Eds. - Oxford : Blackwell, 1983. - pp. 69-93.

ANDREWS (M.). - The partitioning of nitrate assimilation between root and shoot of higher plants. - Plant Cell Environ., vol. 9, 1986, pp. 511-519.

ATTIWIL (P.M.), ADAMS (M.A.). - Nutrient cycling in forest. - New Phytol., vol. 124, 1993, pp. 561-582.

BAJWA (R.), ABUARGHUB (S.), READ (D.J.). - The biology of mycorrhiza in the Ericaceae. X. The utilization of proteins and the production of proteolytic enzymes by the mycorrhizal plants. - New Phytol., vol. 101, 1985, pp. 469-486.

BECKER (J.M.), NAIDER (F.R.). - Fungal peptide transport as drug delivery system. In: Peptide-based drug design. Controlling transport and metabolism / M.D. Taylor, G.L. Amidon Eds. - Washington: American Chemical Society, 1995. - pp. 369-384.

BEDELL (J.P.), CHALOT (M.), BRUN (A.), BOTTON (B.). - Purification and properties of glutamine synthetase from Douglas fir roots. - Physiol. Plant., vol. 94, 1995, pp. 597-604.

BENDING (G.D.), READ (D.J.). - The structure and function of the vegetative mycelium of ectomycorrhizal plants. V. Foraging behaviour and translocation of nutrients from exploited organic matter. - New Phytol., vol. 130, 1995a, pp. 401-409.

BENDING (G.D.), READ (D.J.). - The structure and function of the vegetative mycelium of ectomycorrhizal plants. VI. Activities of nutrient mobilizing enzymes in birch litter colonized by Paxillus involutus (Fr.) Fr.. - New Phytol., vol. 130, 1995b, pp. 410-417.

BLAUDEZ (D.), CHALOT (M.), DIZENGREMEL (P.), BOTTON (B.). - Structure and function of the ectomycorrhizal association between Paxillus involutus and Betula pendula. II. Metabolic modifications during mycorrhiza formation. New Phytol., 1997 (sous presse).

BOTTON (B.), CHALOT (M.). - Nitrogen assimilation : Enzymology in ectomycorrhizas. In : Mycorrhiza : structure, function, molecular biology and biotechnology / A.H. Varma, B. Hock Eds. - Berlin, Heidelberg : Springer Verlag, 1995. - pp. $325-363$ 


\section{Le fonctionnement des symbioses mycorhiziennes}

BOTTON (B.), CHALOT (M.), GARNIER (A.), MARTIN (F.). - L'Assimilation de l'azote minéral chez les ectomycorhizes. Acta bot. Gallica, vol. 141, 1994, pp. 469-481.

BUSH (D.R.). - Proton-coupled sugar and amino acid transporters in plants. - Ann. Rev. Plant Physiol. Plant Mol. Biol., vol. 44, 1993, pp. 513-542.

CHALOT (M.), BRUN (A.), BOTTON (B.), SÖDERSTRÖM (B.). - Kinetics, energetics and specificity of the general amino acid transporter from the ectomycorrhizal fungus Paxillus involutus. - Microbiology, vol. 142, 1996, pp. $1749-1756$.

CHALOT (M.), KYTOVIITA (M.M.), BRUN (A.), FINLAY (R.D.), SÖDERSTRÖM (B.). - Factors affecting amino acid uptake by the ectomycorrhizal fungus Paxillus involutus. - Mycol. Res., vol. 99, 1995, pp. 1131-1138.

COHEN (B.L.). - Transport and utilization of proteins by fungi. In : Microorganisms and nitrogen sources / J.W. Payne Ed. . - Chichester (England) : John Wiley and Sons Ltd., 1980, pp. 411-430.

COLPAERT (J.), VAN ASSHE (J.A.), LUITJENS (A.K.). - The growth of the extramatrical mycelium of ectomycorrhizal fungi and the growth response of Pinus sylvestris L. - New Phytol., vol. 120, 1992, pp. 127-135.

COLPAERT (J.), VAN TICHELEN (K.). - Decomposition, nitrogen and phosphorus mineralization from beech leaf litter colonized by ectomycorrhizal or litter-decomposing basidiomycetes. - New Phytol., vol. 134, 1996a, pp. 123-132.

COLPAERT (J.), VAN LAERE (A). - A comparison of the extracellular enzyme activities of two ectomycorrhizal and a leaf-saprophytic basidiomycete colonizing beech leaf litter. - New Phytol., vol. 134, 1996b, pp. 133-141.

CONJEAUD (C.). - Étude de l'influence de l'ectomycorhization sur l'utilisation du carbone par le Pin maritime (Pinus pinaster). Interactions avec les nutritions phosphatée et azotée. - Montpellier : Université de Montpellier II, 1996. $351 \mathrm{p}$. (Thèse).

EK $(\mathrm{H}$.). - The influence of nitrogen fertilization on the carbon economy of Paxillus involutus in ectomycorrhizal association with Betula pendula. - New Phytol., vol. 135, 1997, pp. 133-142.

EK (H.), ANDERSSON (S.), ARNEBRANT (K.), SÖDERSTRÖM (B.). - Growth and assimilation of $\mathrm{NH}_{4}^{+}$and $\mathrm{NO}_{3}-$ by Paxillus involutus in association with Betula pendula and Picea abies as affected by substrate pH. - New Phytol., vol. 128,1994 , pp. 629-637.

EL-BADAOUI (K.), BOTTON (B.). - Production and characterization of exocellular proteases in ectomycorrhizal fungi. Annales des Sciences forestières, vol. 46, 1989, pp. 728-730.

FINLAY (R.D.), EK (H.), ODHAM (G.), SÖDERSTRÖM (B.). - Mycelial uptake, translocation and assimilation of nitrogen from ${ }^{15} \mathrm{~N}$-labelled ammonium by Pinus sylvestris plants infected with four different ectomycorrhizal fungi. - New Phytol., vol. 110, 1988, pp. 59-66.

FINLAY (R.D.), EK (H.), ODHAM (G.), SÖDERSTRÖM (B.). - Uptake, translocation and assimilation of nitrogen from ${ }^{15} \mathrm{~N}-$ labelled ammonium and nitrate sources by intact ectomycorrhizal systems of Fagus sylvatica infected with Paxillus involutus. - New Phytol., vol. 113, 1989, pp. 47-55.

FRANCE (R.C.), REID (C.P.P.). - Interactions of nitrogen and carbon in the physiology of ectomycorrhizae. - Canadian Journal of Botany, vol. 61, 1983, pp. 964-984.

FROMMER (W.B.), KWART (M.), HIRNER (B.), FISCHER (W.N.), HUMMEL (S.), NINNEMANN (O.). - Transporters for nitrogenous compounds in plants. - Plant Mol. Biol., vol. 26, 1994, pp. 1651-1670.

GENETET (I.), MARTIN (F.), STEWART (G.R.). - Nitrogen assimilation in mycorrhizas. Ammonium assimilation in the N-starved ectomycorrhizal fungus Cenococcum geophilum. - Plant Physiol., vol. 76, 1984, pp. 395-399.

GOJON (A.), PLASSARD (C.), BUSSI (C.). - Root / shoot distribution of $\mathrm{NO}_{3}{ }^{-}$assimilation in herbaceous and woody species. In : A whole plant perspective of carbon-nitrogen interactions / J. Roy et E. Garnier Eds. - The Hague : SPB Academic Publishing, 1994. - pp. 131-147.

HARLEY (J.L.). - Nutrient absorption by ectomycorrhiza. - Physiol. vég., vol. 16, 1978, pp. 533-545.

HARLEY (J.L.), SMITH (S.E.). - Mycorrhizal symbiosis. - London : Academic Press, 1983.

HORAK (J.). - Amino acid transport in eukaryotic microorganisms. - Biochim. Biophys. Acta, vol. 864, 1986, pp. $223-256$.

KRONZUCKER (H.J.), SIDDIQI (M.Y.), GLASS (A.D.M.). - Conifer root discrimination against soil nitrate and the ecology of forest succession. - Nature, vol. 385, 1997, pp. 59-61.

MARSCHNER (H.), HAÜSSLING (M.), GEORGE (E.). - Ammonium and nitrate uptake rates and rhizosphere-pH in non-mycorrhizal roots of Norway spruce (Picea abies (L.) Karst.). - Trees, vol. 5, 1991, pp. 14-21.

MARTIN (F.), BOTTON (B.). - Nitrogen metabolism of ectomycorrhizal fungi and ectomycorrhizas. - Adv. Plant Pathol., vol. 9, 1993, pp. 83-102.

MARTIN (F.), STEWART (G.R.), GENETET (I.), LE TACON (F.). - Assimilation of ${ }^{15} \mathrm{NH}_{4}{ }^{+}$by beech (Fagus sylvatica L.) ectomycorrhizas. - New Phytol., vol. 102, 1986, pp. 85-94.

MARTIN (F.), RAMSTEDT (M.), SÖDERHÄLL (K.). - Carbon and nitrogen metabolism in ectomycorrhizal fungi and ectomycorrhizas. - Biochimie, vol. 69, 1987, pp. 569-581.

MIFLIN (B.J.), LEA (P.J.). - Ammonia assimilation. In : The Biochemistry of Plants. A Comprehensive Treatise / B.J. Miflin Ed. .- New-York : Academic Press, 1980. - Vol. 5, pp. 169-202.

OAKS (A.), HIREL (B.). - Nitrogen metabolism in roots. - Ann. Rev. Plant. Physiol., vol. 36, 1985, pp. 345-365.

PLASSARD (C.), BARRY (D.), ELTROP (L.), MOUSAIN (D.). - Nitrate uptake in maritime pine (Pinus pinaster) and the ectomycorrhizal fungus Hebeloma cylindrosporum : effect of ectomycorrhizal symbiosis. - Canadian Journal of Botany, vol. 72, 1994, pp. 189-197.

PLASSARD (C.), MARTIN (F.), MOUSAIN (D.), SALSAC (L.). - Physiology of nitrogen assimilation by ectomycorrhizae. In : Physiological and genetical aspects of mycorrhizae / V. Gianinazzi-Pearson et S. Gianinazzi Eds. - Paris: INRA, 1986. - pp. 111-120. 
PLASSARD (C.), MOUSAIN (D.), SALSAC (L.). - Mesure in vivo et in vitro de l'activité nitrite réductase dans les thalles d'un champignon basidiomycète (Hebeloma cylindrosporum Romagn.). - Physiol. vég., vol. 22, 1984, pp. 147-154.

PLASSARD (C.), SCHEROMM (P.), MOUSAIN (D.), SALSAC (L.). - Assimilation of mineral nitrogen and ion balance in the two partners of ectomycorrhizal symbiosis : data and hypothesis. - Experientia, vol. 47, 1991, pp. 340-349.

RAMSTEDT (M.), SÖDERHÄLL (K.). - Protease, phenoloxidase and pectinase activities in mycorrhizal fungi. - Trans. Br. Mycol. Soc., vol. 81, 1983, pp. 157-161.

READ (D.J.). - Mycorrhizas in ecosystems. - Experientia, vol. 47, 1991, pp. 376-390.

ROBINSON (S.A.), SLADE (A.P.), FOX (G.G.), PHILLIPS (R.), RATCLIFFE (R.G.), STEWART (G.R.). - The role of glutamate dehydrogenase in plant nitrogen metabolism. - Plant Physiol., vol. 95, 1991, pp. 509-516.

ROOS (W.). - Kinetic properties, nutrient-dependent regulation and energy coupling of amino acid transport systems in Penicillium cyclopium. - Biochim. Biophys. Acta, vol. 978, 1989, pp. 119-133.

ROWE (J.S.). - Forest regions of Canada. - Ottawa : Canadian Forestry Service Publication, n $1300,1972$.

RYGIEWICZ (P.T.), BLEDSOE (C.S.), ZASOSKI (R.J.). - Effects of ectomycorrhizae and solution pH on [ $\left.{ }^{15} \mathrm{~N}\right]$ ammonium uptake by coniferous seedlings. - Canadian Journal of Forest Research, vol. 14, 1984a, pp. 885-892.

RYGIEWICZ (P.T.), BLEDSOE (C.S.), ZASOSKI (R.J.). - Effects of ectomycorrhizae and solution pH on [ $\left.{ }^{15} \mathrm{~N}\right]$ nitrate uptake by coniferous seedlings. - Canadian Journal of Forest Research, vol. 14, 1984b, pp. 893-899.

SIMS (A.P.), FOLKES (B.F.). - A kinetic study of the assimilation of ${ }^{15} \mathrm{~N}$-ammonia and the synthesis of amino acids in an exponentially growing culture of Candida utilis. - Proc. R. Soc. B., vol. 159, 1964, pp. 479-502.

SOPHIANOPOULOU (V.), DIALLINAS (G.). - Amino acid transporters of lower eukaryotes : regulation, structure and topogenesis. - FEMS Microbiol Rev., vol. 16, 1995, pp. 53-75.

STARK (J.M.), HART (S.C.). - High rates of nitrification and nitrate turnover in undisturbed coniferous forests. - Nature, vol. 385, 1997, pp. 61-64.

STEWART (G.R.), PEARSON (J.), KERSHAW (J.L.), CLOUGH (E.C.M.). - Biochemical aspects of inorganic nitrogen assimilation by woody plants. - Annales des Sciences forestières, vol. 46, 1989, pp. 631-647.

VÉZINA (L.P.), MARGOLIS (H.A.). - Purification and properties of glutamine synthetase in leaves and roots of Pinus banksiana Lamb. - Plant Physiol., vol. 94, 1990, pp. 657-664.

WAGNER (F.), GAY (G.), DEBAUD (J.C.). - Genetic variation of nitrate reductase activity in mono- and dikaryotic populations of the ectomycorrhizal fungus, Hebeloma cylindrosporum Romagnési. - New Phytol., vol. 113, 1989, pp. $259-264$.

WALLSGROVE (R.M.). - Enzymes of inorganic nitrogen metabolism. The roles of glutamine synthetase and glutamate synthase in nitrogen metabolism of higher plants. In : Inorganic Nitrogen Metabolism / W.R. Ullrich, P.J. Aparacio, P.J. Syrett, F. Castillo Eds. - Berlin : Springer Verlag, 1987. - pp. 167-193.

ZHU (H.), GUO (D.C.), DANCIK (B.P.). - Purification and characterization of an extracellular acid proteinase from the ectomycorrhizal fungus Hebeloma crustuliniforme. - Appl. Environ. Microbiol., vol. 56, 1990, pp. 837-843.

\section{LE RÔLE DES ECTOMYCORHIZES DANS LA NUTRITION AZOTÉE DES ARBRES FORESTIERS (Résumé)}

Dans les régions tempérées et boréales, la plupart des essences sylvicoles croît sur des sols très pauvres en azote utilisable. De ce fait, l'établissement de la symbiose ectomycorhizienne est indispensable à la survie et au développement des arbres. Les champignons ectomycorhiziens ont la capacité d'absorber l'azote minéral et certaines formes d'azote organique et de le transporter par l'intermédiaire du mycélium extramatriciel vers les cellules de la racine. Dans cet article, nous présentons les mécanismes biochimiques qui contrôlent l'absorption, l'assimilation et le transport de l'azote organique et minéral. Nous discutons également les processus permettant l'intégration de ces voies métaboliques dans la biologie de la plante-hôte. La meilleure utilisation par la plante ectomycorhizée du stock d'azote disponible dans les sols a un rôle écologique fondamental dans le cycle de l'azote des peuplements forestiers.

\section{THE ROLE OF ECTOMYCORRHIZAE IN NITROGEN NUTRITION OF FOREST TREES (Abstract)}

Low nitrogen $(\mathrm{N})$ availability appears to limit the primary production of forests over much of Eurasia and North America. As a consequence, trees have developed mycorrhizal associations alongside a wide range of alternative trophic adaptations (e.g. $\mathrm{N}_{2}$-fixing symbioses) when competing for limited resources of specific nutrients. As ectomycorrhiza is a major nutrient absorbing organ, it is essential to establish the mechanisms and processes whereby $\mathrm{N}$ is mobilized, assimilated and transported within the symbiotic tissues and the associated host plant. This chapter gives a short overview of the processes of acquisition of organic and mineral $\mathrm{N}$ in ectomycorrhizal systems. Then, it briefly introduces the enzymes that catalyze the sequential steps of the pathways of primary $\mathrm{N}$ assimilation. This is followed by a description of the pathways operating in a variety of ectomycorrhizal associations and a discussion of the current understanding of the organization of $\mathrm{N}$-assimilating enzymes in the symbionts and their interaction with the carbon metabolism. Finally, we will discuss the mechanisms controlling the transport of $\mathrm{N}$ between the symbionts. 